Article

\title{
Assessing the Potential Benefits and Limits of Electric Storage Heaters for Wind Curtailment Mitigation: A Finnish Case Study
}

\author{
Mubbashir Ali *, Jussi Ekström and Matti Lehtonen \\ Department of Electrical Engineering and Automation, Aalto University, 02150 Espoo, Finland; \\ jussi.ekstrom@aalto.fi (J.E.); matti.lehtonen@aalto.fi (M.L.) \\ * Correspondence: mubbashir.ali@aalto.fi; Tel.: +358-50-436-7307 \\ Academic Editor: João P. S. Catalão \\ Received: 11 April 2017; Accepted: 12 May 2017; Published: 16 May 2017
}

\begin{abstract}
Driven by policy changes and technological advancement, wind power installations are booming as compared to any other types of power generation. However, the increased penetration of renewable generation in the power systems has resulted in high level of curtailment. Advanced energy storage technologies have been increasingly scrutinized as a feasible mitigation option in smart grids. This paper investigates the potential of mitigating wind generation curtailment via aggregating the domestic electric storage heaters. The key findings show that aggregating domestic thermal storages is a viable option for curtailment mitigation, but with the indispensable caution that mitigation potential significantly saturates as the share of wind generation escalates beyond a certain limit.
\end{abstract}

Keywords: curtailment mitigation; electric storage heaters; wind generation

\section{Introduction}

In the EU, the integration of wind energy in power systems is expanding because of policy-driven targets with a total installed wind power capacity about $150 \mathrm{GW}$ [1]. In 2016 alone, around 13 GW has been added to the system, accounting for about $50 \%$ of the new capacity installation [1]. Though this is a practical step towards a carbon-neutral power system, this must be treated carefully as the systems have already been experiencing elevated levels of curtailment [2]. It is projected that the curtailment level will jump from 0.4 TWh (2020) to 9.3 TWh (2030) [3].

Recently, curtailment mitigation solutions such as demand response [4-6], active network management $[7,8]$, network reinforcement $[9,10]$, market rules and support schemes [11], and storage technologies [12-17] have been investigated in literature. While each option has pros and cons, storage technologies would be imperative to ensure a tolerable level of curtailment. The objective of options in curtailment mitigation is to increase the system's flexibility to accommodate the variability and uncertainty of renewable power generation.

In this context, in order to better cope with the curtailment mitigation challenge, domestic thermal energy storages (for space heating and domestic hot water usage) are a viable proposition as compared to the advanced energy storage technologies such as compressed air energy storage and battery technology. The reason is twofold; firstly, the cost of advanced energy storage systems is higher and secondly, the systems deteriorate with continual cyclic charging and discharging. However, electric storage heater installations are ubiquitous in the household sector in Finland. These installations have a large thermal storage tank (with typical storage units around 300-500 L) to store hot water during off-peak hours and could be employed to allow excess wind production. Aggregating the large population of these storage heaters and integrating additional distributed thermal storage can provide 
extra capacity (increased power and energy limits) to accommodate large-scale renewable generation; nonetheless, it is imperative to estimate the potential benefits and limits of this solution before making any investment decision.

The research scope of this article is the comprehensive evaluation of curtailment mitigation potential via aggregating customer-owned thermal storages. Using a Finnish case study, a mathematical formulation of the proposed framework is presented to minimize the wind energy curtailment given the total distributed thermal storage capacity in the system. To demonstrate the seasonal impact of thermal storage selection on wind curtailment, the simulations are performed covering winter and summer seasons. Furthermore, to account for the uncertainty and variability of wind energy, the simulations are conducted for probable scenarios of wind generation; the results are then showcased bounded by the confidence interval.

The remainder of this paper is organized as follows: Section 2 describes the wind generation and space heating estimation methodologies; Section 3 introduces the framework for investigating the curtailment mitigation potential through aggregating customer-owned thermal storages; case studies based on the Finnish system are presented in Section 4; and Section 5 presents the closing remarks.

\section{Modeling Methodologies}

In this section, wind generation modeling and space heating estimation models are presented.

\subsection{Wind Generation Model}

In order to determine the effects of aggregating customer-owned thermal storages on wind energy curtailment, representative wind generation time series are required to be simulated. In this paper, time series of wind generation with varying levels of penetration in the system are obtained using a well-known statistical approach as utilized in previous works $[18,19]$. This is centered on a statistical method combining probability integral transformations and time-series modeling, thereby simulating wind speed discrete-time data for a new group of wind turbines. In the next step, using a wind speed time series and a wind turbines model (specifications differ for each turbine type and wind farm), a wind generation time series is simulated.

This wind generation model is modified from work in [18] as it accounts the real wind power installation scenarios in Finland until the beginning of 2016. The 2016 generation structure is used as a base for the simulated scenarios which consists of an aggregate of $1008 \mathrm{MW}$ of generation capacity with 377 individually modeled wind turbines with real world specifications (turbine technical information including e.g., power curve parameters and nominal power). The model distinctly considers the geographical spread of multiple wind farms and different wind turbines. It is assumed that the average capacity factor for the aggregate wind generation is 0.282 , which is in line with the current experience. The wind generation is scaled for each of the considered scenarios (100 years) based on the aggregate electricity generation in Finland during 2015, excluding imports and exports. Figure 1 presents the simulated wind generation with varying levels of penetration $(10 \%, 30 \%, 50 \%$ and $70 \%$ of total generation) in the system. 


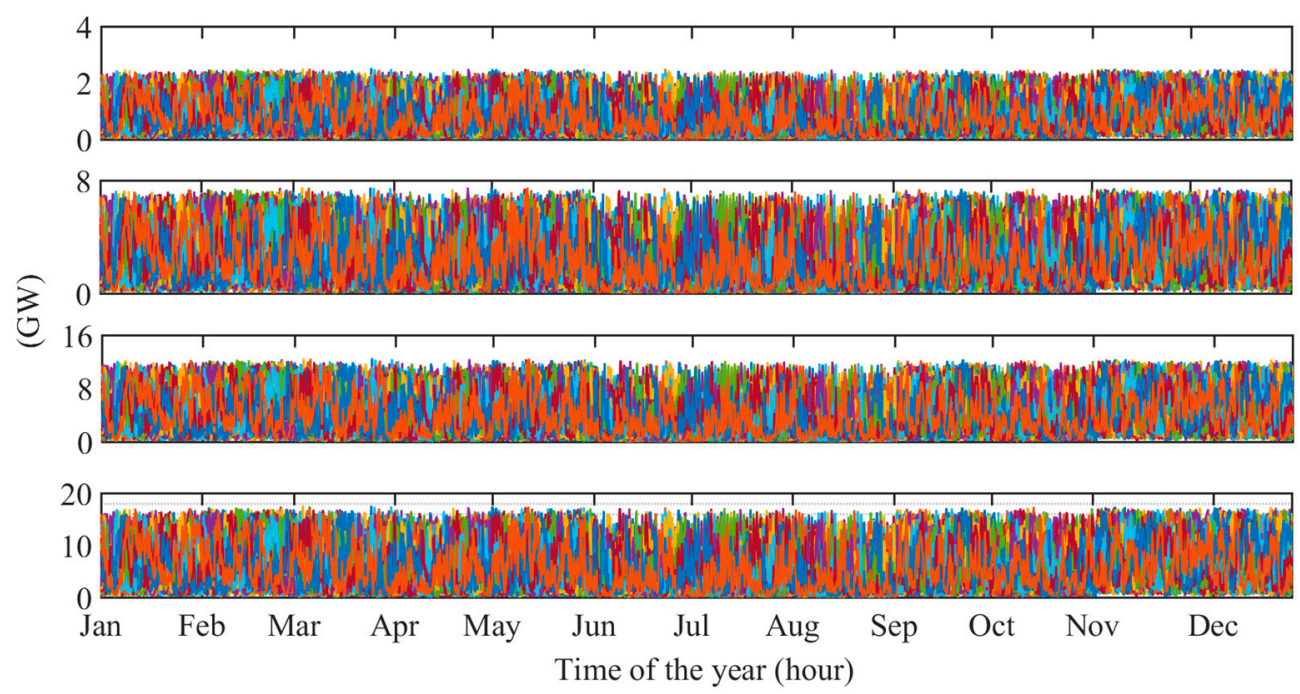

Figure 1. Time series of the simulated wind power generation for varying level of penetration in the system (From top to bottom: 10\%, 30\%, 50\% and 70\% penetration scenarios).

\subsection{Space Heating Modeling}

This subsection presents a 2-capacity building model, as illustrated in Figure 2, to estimate the space heating requirement [7].

It is a reasonably accurate model to derive the space heating requirement of a typical detached house. As presented in Figure 2, there are two distinct specific heat capacities, $C_{a}$ which denotes the heat capacity of air, while $C_{m}$ represents the thermal masses of house structures. The thermal capacitance, $C_{m}$ is much larger than $C_{a}$ and hence has a dominating role to provide thermal inertia and it is lumped in the mass node point, and portrays roughly the mean thermal mass temperature of the house. In the 2-capacity model, there are different temperature nodes, which are coupled by either heat conductance or by a heat capacity flow. Infiltration/exfiltration (passage of air) is connected between the external and indoor ambient temperatures. Therefore, it is safe to assume there is no warming of the infiltration air in the house structure and the air flow has the same temperature as the outside air. In addition, it is supposed that the windows of the houses have an insignificant thermal mass compared with the rest of the building envelope, whereas the space heating system is assumed to be convective.

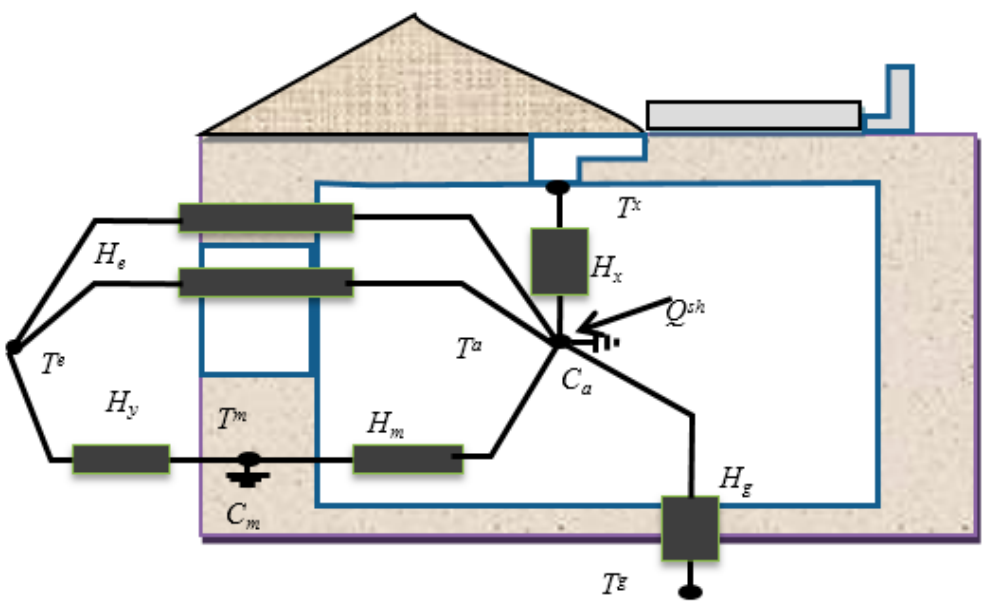

Figure 2. Thermal model of a detached house. 
The representation of a 2-capacity building thermal model is related by first-order differential Equations (1) and (2).

$$
\begin{gathered}
C_{a} \frac{\partial T^{a}}{\partial t}=H_{e}\left(T^{e}-T^{a}\right)+H_{m}\left(T^{m}-T^{a}\right)+H_{g}\left(T^{g}-T^{a}\right)+H_{x}\left(T^{x}-T^{a}\right)+Q_{t}^{s h} \\
C_{m} \frac{\partial T^{m}}{\partial t}=H_{m}\left(T^{a}-T^{m}\right)+H_{y}\left(T^{e}-T^{m}\right)
\end{gathered}
$$

The above Equations (1) and (2) can be transformed into an approximately equivalent discrete time model and can be solved for unknown indoor ambient and thermal mass temperatures $T^{a}$ and $T^{m}$ respectively. The exact solution for the above differential equation is given by (3) and (4).

$$
\begin{aligned}
T_{t}^{a} & =\frac{a_{12} b_{2}-a_{22} b_{1}}{a_{12} a_{21}-a_{11} a_{22}} \\
T_{t}^{m} & =\frac{a_{21} b_{1}-a_{11} b_{2}}{a_{12} a_{21}-a_{11} a_{22}}
\end{aligned}
$$

where,

$$
\begin{gathered}
a_{11}=1+\frac{\Delta t}{C_{a}}\left(H_{e}+H_{m}+H_{g}+H_{x}\right) \\
a_{12}=-\frac{\Delta t}{C_{a}} H_{m} \\
a_{21}=-\Delta H_{m} \\
a_{22}=1+\frac{\Delta t}{C_{m}}\left(H_{m}+H_{y}\right) \\
b_{1}=T_{t-1}^{a}+\frac{\Delta t}{C_{a}}\left[H_{e} T_{t}^{e}+H_{g} T_{t}^{g}+H_{x} T_{t}^{x}+Q_{t}^{s h}\right] \\
b_{2}=T_{t-1}^{m}+\frac{\Delta t}{C_{m}} H_{e} T_{t}^{e}
\end{gathered}
$$

The thermal model parameters were identified by abating the difference between the reference step response obtained from IDA (Dynamic multi-zone simulation environment for the study of buildings thermal indoor climate. http:/ / www.equa.se/en/ida-ice) and the 2-capacity building model step-response. The optimal combination of the above model parameters was obtained via the classical search technique.

\section{Framework}

This section presents the framework enabling the quantification of thermal energy storages and their aggregated potential for mitigating the wind curtailment. Mathematically, the objective function can be formulated as follows.

minimize WEC

$$
\begin{aligned}
& W E C=\sum_{t}\left[\left(X_{t}^{\text {conv }}+X_{t}^{\text {wind }}\right)-\left(D_{t}^{\text {crit }}+D_{t}^{\text {heating }}\right)\right] \\
& \exists W E C \geq 0, \forall t \in T
\end{aligned}
$$

The first term in the objective function represents the total generation in the system, wind, and non-renewable generation in the system, whereas the latter represents the system demand, critical and heating demand in a given time period.

The objective function (11) is subjected to three set of constraints: thermal comfort constraints, energy storage characterization, and those due to system constraints. They are stated and discussed in the following. 


$$
\begin{gathered}
T_{t}^{a}=\frac{T_{t-1}^{a}+\frac{\Delta t}{C_{a}}\left[H_{m} T_{t-1}^{m}+H_{e} T_{t}^{e}+H_{g} T_{t}^{g}+H_{x} T_{t}^{x}+Q_{t}^{s h}\right]}{1+\frac{\Delta t}{C_{a}}\left(H_{m}+H_{e}+H_{g}+H_{x}\right)} \\
T_{t}^{m}=\frac{T_{t-1}^{m}+\frac{\Delta t}{C_{m}}\left(H_{m} T_{t-1}^{a}+H_{y} T_{t}^{e}\right)}{1+\frac{\Delta t}{C_{m}}\left(H_{m}+H_{y}\right)} \\
\left(T_{n, t}^{s e t}-\frac{\phi_{n}}{2}\right) \leq T_{n, t}^{a} \leq\left(T_{n, t}^{s e t}+\frac{\phi_{n}}{2}\right), \forall t \in T, \forall n \in N \\
\left(S o C_{n, t+1}^{T S}-S o C_{n, t}^{T S}\right) \beta^{n}=\left(P_{n, t}^{T S}-Q_{n, t}^{s h}-Q_{n, t}^{d h w}\right) \Delta t-\xi_{n, t}, \forall t \in T, \forall n \in N \\
0 \leq P_{n, t}^{T S} \leq P_{n, t}^{T S, \max }, \forall t \in T, \forall n \in N \\
S o C_{n, t}^{T S, \min } \leq S o C_{n, t}^{T S} \leq S o C_{n, t}^{T S, \max } \\
\xi_{n, t}=\eta^{n} S o C_{n, t-1}^{T S}, \forall t \in T, \forall n \in N \\
D_{t}^{h e a t i n g}=\sum_{n} P_{n, t}^{T S}, \forall t \in T \\
D_{t}^{c r i t}=\sum_{n} P_{n, t}^{c r i t}, \forall t \in T \\
P_{n, t}^{c r i t}+P_{n, t}^{T S} \leq v_{n}, \forall n \in N, \forall t \in T
\end{gathered}
$$

Equations (12) and (13) are approximated versions of (3) and (4) to estimate the space heating requirement with less computation; however, accuracy is not compromised. The constraint (14) establishes that indoor ambient temperature remains within the predefined upper and lower temperature limits, hence respecting the customers' thermal comfort at all times. Constraint (15) determines the thermal storage charging behavior. The rated charging power of energy storage unit is bounded by (16), while (17) bounds the upper and lower limits of state of charge of energy storage, respectively. Expression (18) calculates the energy losses of thermal storage, which depends on efficiency of storage unit. The total demand of the flexible load group, namely, space heating and domestic hot water, and the critical load group is determined by (19) and (20). Constraint (21) ascertains that the total household demand remains under the demand limit dictated by the household main fuse rating.

The above model is based on a linear programming format and can be solved using linear programming via CPLEX solver using Matlab/GAMS interface. Figure 3 clarifies the process and modules graphically. 


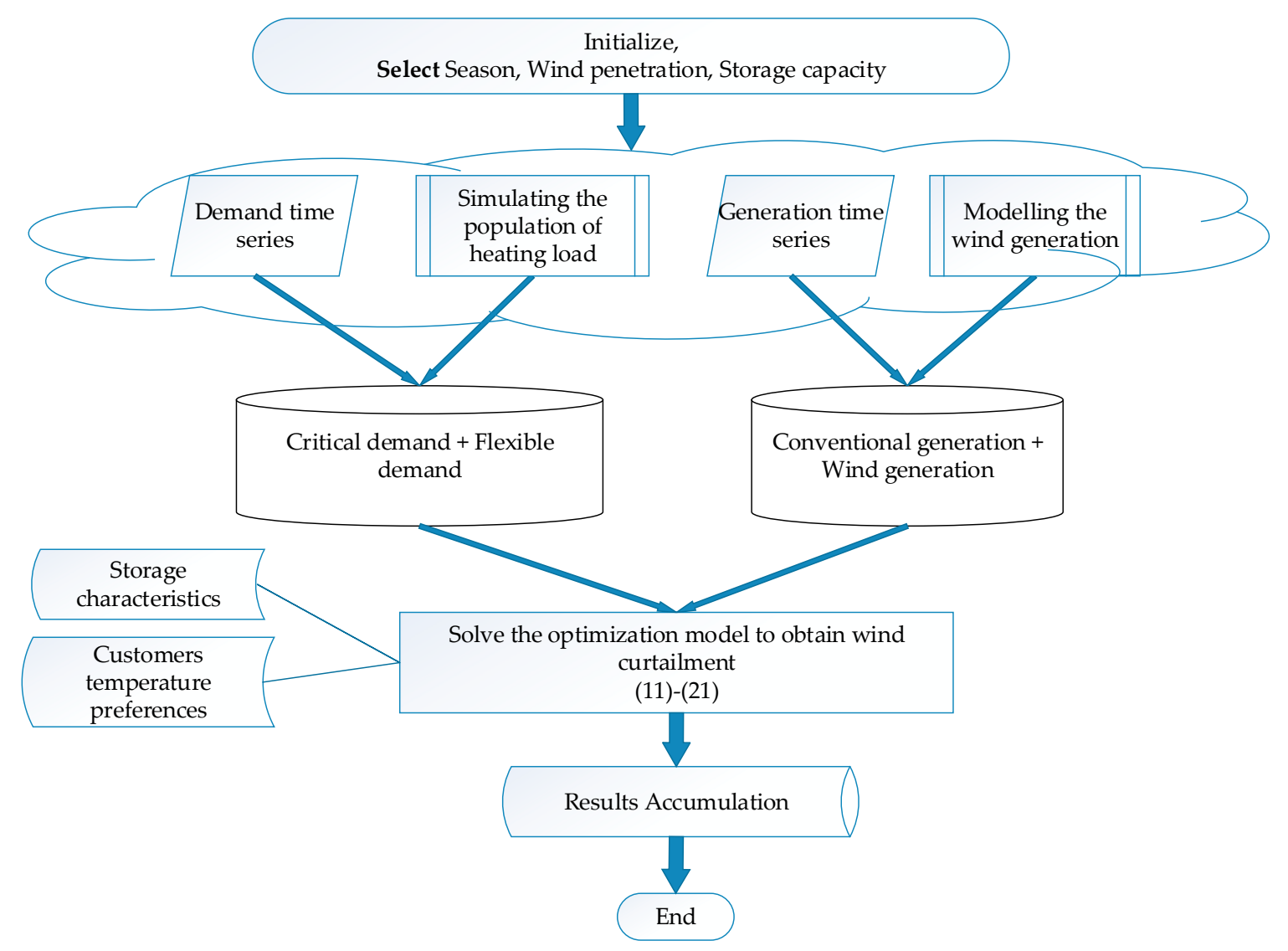

Figure 3. Flowchart illustrating the process.

\section{Case Study}

The case study is based on the Finnish system. To comprehensively evaluate the potential benefits of aggregating domestic thermal storages for wind curtailment mitigation, simulations are conducted by varying the storage size for two different weather situations, namely winter and summer. In addition, the problem is solved for four scenarios (10\% wind, $30 \%$ wind, $50 \%$ wind, and $70 \%$ wind), which represents the different levels of wind penetration in the system. In the basic simulation, the purpose is to highlight the impact of seasonal variation on thermal storage capacity potential for curtailment mitigation given varying wind penetration; therefore, a single run of wind generation is considered. Later, we account for issues of uncertainty by solving the problem for a number of wind simulation runs in order to determine the confidence interval bounds of the results.

\subsection{Input Data Preparation}

The electrical demand time series is obtained from the transmission system operator for the year of 2015. Next, we construct the baseline of the domestic heating load by using the building model introduced in Section 2.2. The thermal parameters of the existing building stock in Finland is obtained from [20] while outside temperature profiles are obtained from [21]. It is to be noted that the mean indoor ambient temperature is set to be $21^{\circ} \mathrm{C}$. The domestic hot water usage aggregated load is constructed based on the typical consumption of a Finnish household [22], with the assumption that hot water consumption is the same on a daily level and average consumption is the same per customer. In the simulation, it is assumed that 300,000 storage heating units are presented in the system that can be used for both space heating and domestic hot water. The parameters of the storage heating units are set as follows: Power rating $P_{n}^{T S, \max }=8 \mathrm{~kW}$ (storage capacity $=1$ day) $/ 16 \mathrm{~kW}$ (otherwise) and storage loss coefficient $\eta^{n}=1 \%$. Since the study is conducted considering a future grids scenario, it is assumed 
that there are two million EVs in the system while their charging is uncontrolled and follows a typical pattern as modelled in [23]. Figure 4a,b gives the time series of demand data in winter and summer respectively.

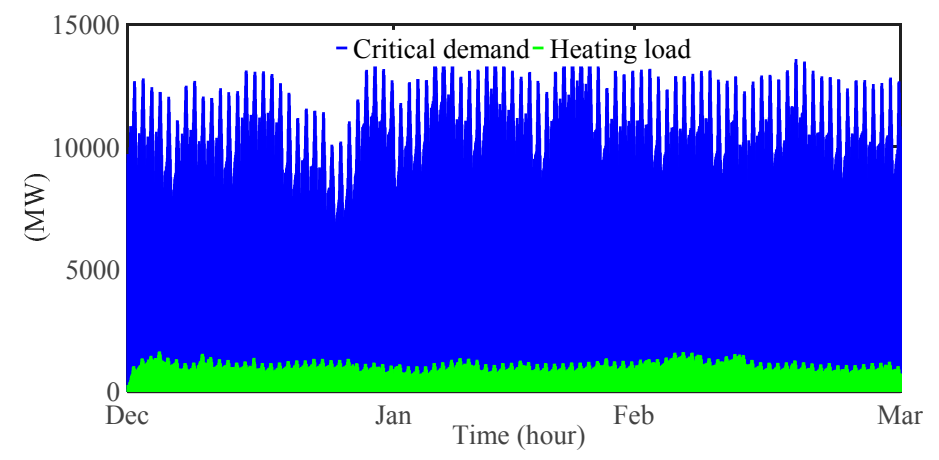

(a)

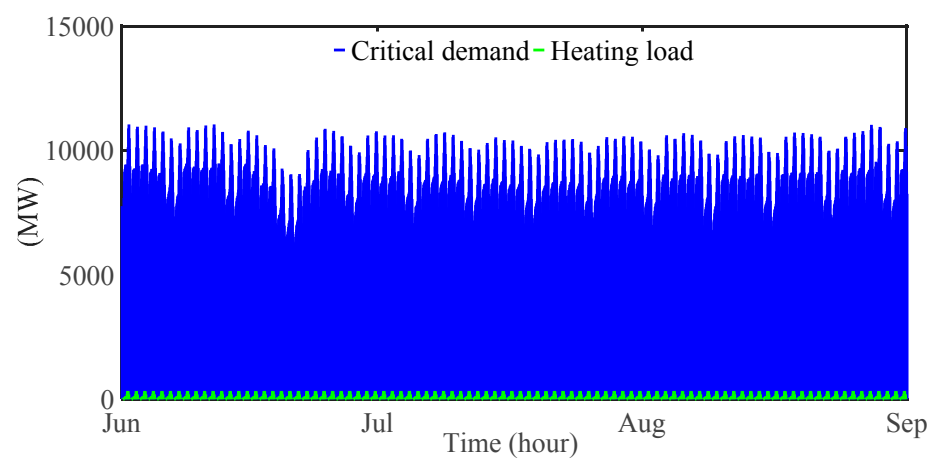

(b)

Figure 4. Demand data used in the simulations (a) winter (b) summer.

The generation time series is constructed by replacing the fraction of conventional generation with wind generation penetration. The resulting system level production scenarios for winter and summer are shown in Figure 5a,b respectively.

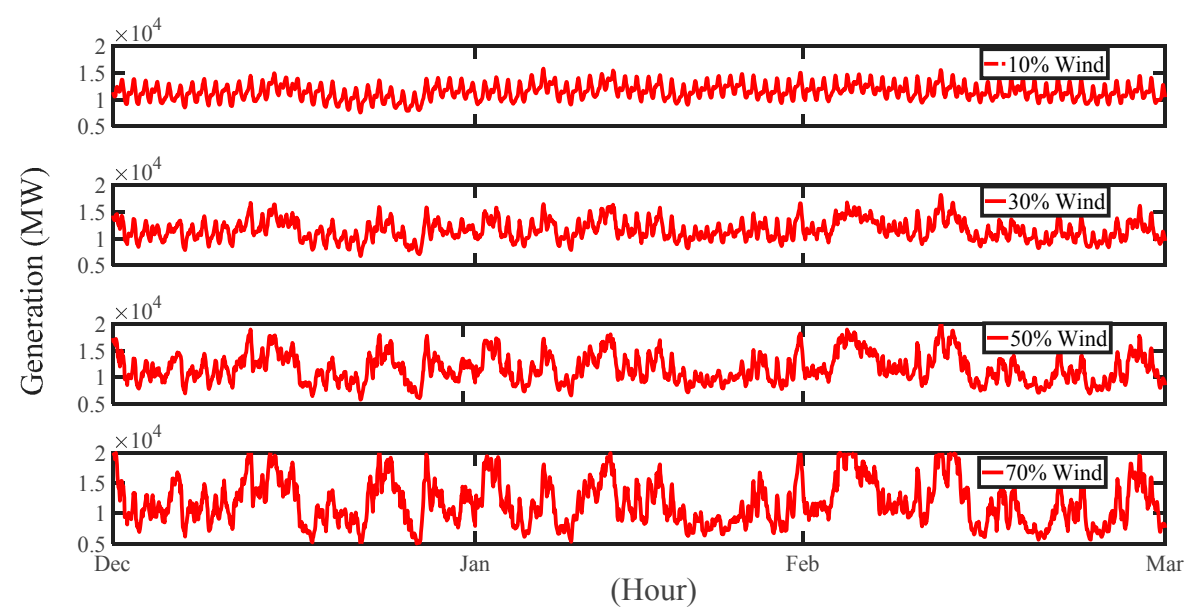

(a)

Figure 5. Cont. 


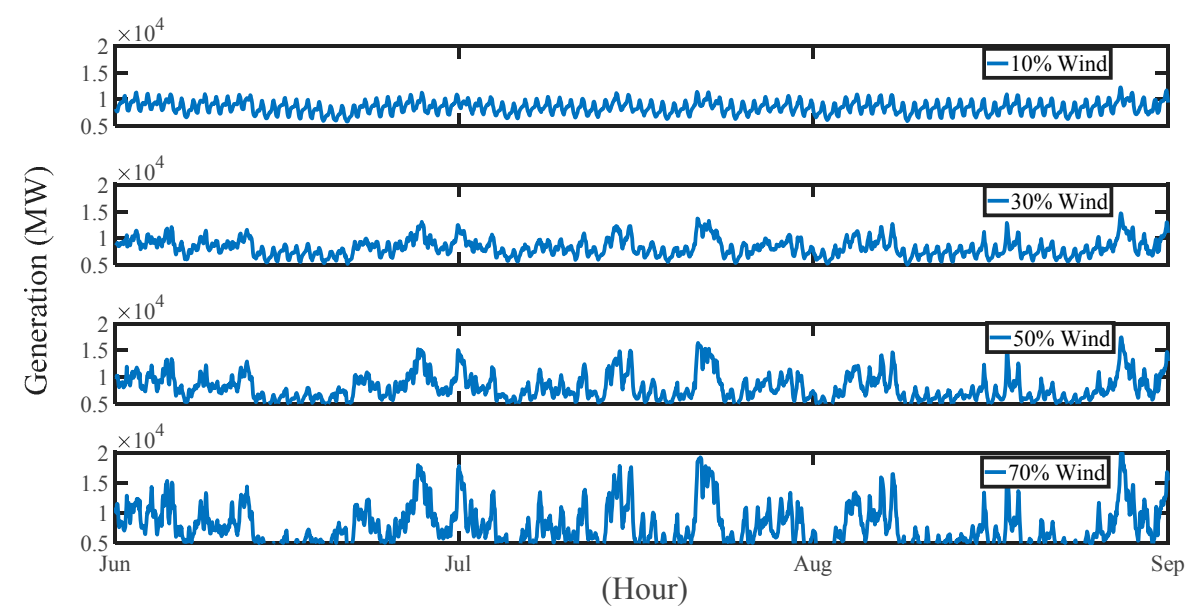

(b)

Figure 5. Generation profiles used in the simulations (a) winter (b) summer.

\subsection{Simulation Results}

In this section, the impact of aggregating domestic thermal storages for curtailment mitigation is discussed. The problem presented in the proposed framework is solved for a definite energy storage capacity (i.e., 1 day, 2 days, and so forth) and respective energy curtailment levels are obtained. It is to be noted that the customer-owned thermal storage is expressed as a function of days. (Where 1 day of storage implies that the customer can store the heating demand for one typical winter day i.e., $60 \mathrm{kWh}$ ).

The evolution of wind curtailment in the system as a function of storage capacity for different wind penetration rates $(10 \%, 30 \%, 50 \%$ and $70 \%)$ is shown in Figure 6 . As can be seen from the results, the curtailment mitigation potential is saturated, and benefits of adding more storage beyond a certain capacity is not useful. This trend becomes more dominant with the increase in wind penetration in the system. For instance, in the $50 \%$ and $70 \%$ wind scenarios where wind penetration is high, the benefits saturate after a few days of storage capacity. In addition, this can also have a substantial influence when deciding the global optimal storage capacity. It is to be noted that the seasonal load variation influences the curtailment rate and will consequently influence the energy storage selection. As can be seen from Figure 6, the potential saturated quickly in summer (dotted lines) as compared to winter (solid lines). The primary reason for this behavior is that the flexible heating load represents only a small fraction of total load during summer.

The curtailments level obtained w.r.t thermal energy storage capacity are presented in Table 1. It can be seen that significant levels of curtailment were present in the system even with larger storages when a large amount of wind was hosted by the system. It is suggested that the storage capacity of 1 week will achieve the $5 \%$ curtailment level with low-to-medium penetration of wind in the system. However, with a higher penetration of wind generation in the system, even weekly levels of storage are inadequate. For instance, a storage capacity of three weeks is unable to achieve an under-5\% curtailment mark when the wind penetration represents $50 \%$ of total generation in the system. 


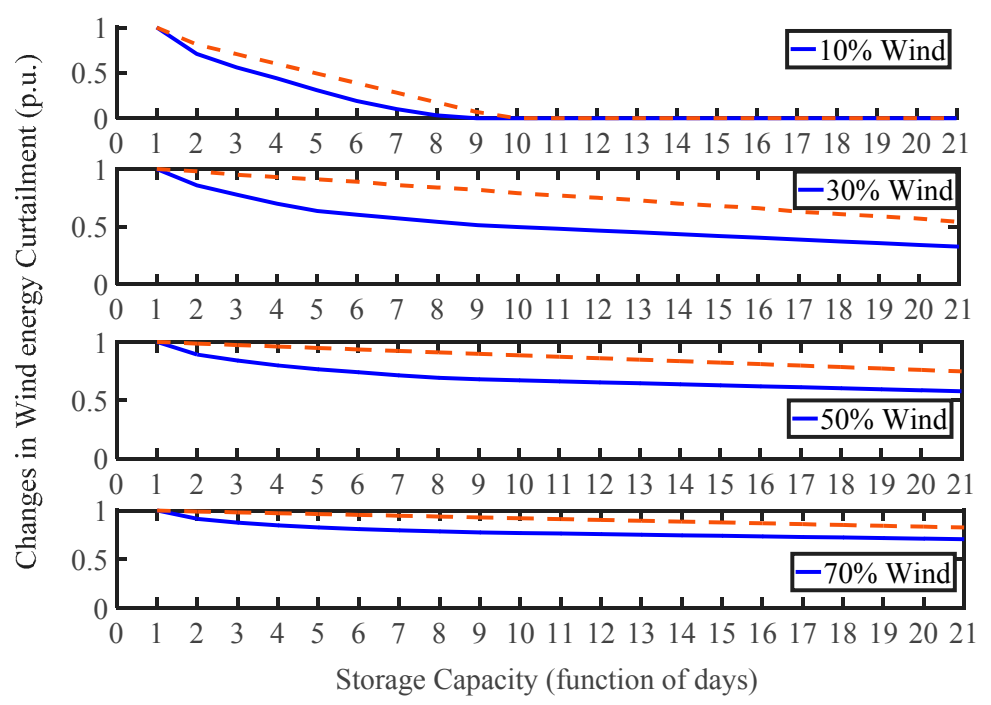

Figure 6. Changes in wind curtailment (expressed as p.u.) for different sizes of thermal storage. (Solid line: Winter; Dotted line: Summer).

Table 1. Overview of the basic results.

\begin{tabular}{ccccccccc}
\hline \multirow{2}{*}{$\begin{array}{c}\text { Storage } \\
\text { Capacity }\end{array}$} & \multicolumn{7}{c}{ Wind Curtailment $\mathbf{( \% )}$} \\
\cline { 2 - 9 } (Days) & $\mathbf{1 0} \%$ Wind & \multicolumn{2}{c}{$\mathbf{3 0} \%$ Wind } & \multicolumn{2}{c}{$\mathbf{5 0} \%$ Wind } & \multicolumn{2}{c}{$\mathbf{7 0} \%$ Wind } \\
\cline { 2 - 9 } & Summer & Winter & Summer & Winter & Summer & Winter & Summer & Winter \\
\hline 1 day & $1.0 \%$ & $1.1 \%$ & $4.5 \%$ & $4.6 \%$ & $8.2 \%$ & $8.5 \%$ & $11.9 \%$ & $12.4 \%$ \\
2 days & $0.8 \%$ & $0.8 \%$ & $4.4 \%$ & $3.9 \%$ & $8.1 \%$ & $7.6 \%$ & $11.7 \%$ & $11.4 \%$ \\
3 days & $0.7 \%$ & $0.6 \%$ & $4.3 \%$ & $3.6 \%$ & $8.0 \%$ & $7.1 \%$ & $11.6 \%$ & $10.9 \%$ \\
4 days & $0.6 \%$ & $0.5 \%$ & $4.2 \%$ & $3.2 \%$ & $7.9 \%$ & $6.8 \%$ & $11.5 \%$ & $10.6 \%$ \\
5 days & $0.5 \%$ & $0.4 \%$ & $4.1 \%$ & $2.9 \%$ & $7.8 \%$ & $6.5 \%$ & $11.4 \%$ & $10.3 \%$ \\
6 days & $0.4 \%$ & $0.2 \%$ & $4.0 \%$ & $2.8 \%$ & $7.6 \%$ & $6.3 \%$ & $11.3 \%$ & $10.1 \%$ \\
7 days & $0.3 \%$ & $0.1 \%$ & $3.9 \%$ & $2.6 \%$ & $7.5 \%$ & $6.1 \%$ & $11.2 \%$ & $9.9 \%$ \\
8 days & $0.2 \%$ & $0.0 \%$ & $3.8 \%$ & $2.5 \%$ & $7.4 \%$ & $5.9 \%$ & $11.1 \%$ & $9.8 \%$ \\
9 days & $0.1 \%$ & $0.0 \%$ & $3.7 \%$ & $2.4 \%$ & $7.3 \%$ & $5.8 \%$ & $11.0 \%$ & $9.6 \%$ \\
10 days & $0.0 \%$ & $0.0 \%$ & $3.6 \%$ & $2.3 \%$ & $7.2 \%$ & $5.7 \%$ & $10.9 \%$ & $9.6 \%$ \\
11 days & $0.0 \%$ & $0.0 \%$ & $3.5 \%$ & $2.2 \%$ & $7.1 \%$ & $5.6 \%$ & $10.8 \%$ & $9.5 \%$ \\
12 days & $0.0 \%$ & $0.0 \%$ & $3.4 \%$ & $2.1 \%$ & $7.0 \%$ & $5.5 \%$ & $10.7 \%$ & $9.4 \%$ \\
13 days & $0.0 \%$ & $0.0 \%$ & $3.3 \%$ & $2.1 \%$ & $6.9 \%$ & $5.5 \%$ & $10.6 \%$ & $9.3 \%$ \\
14 days & $0.0 \%$ & $0.0 \%$ & $3.2 \%$ & $2.0 \%$ & $6.8 \%$ & $5.4 \%$ & $10.5 \%$ & $9.3 \%$ \\
15 days & $0.0 \%$ & $0.0 \%$ & $3.1 \%$ & $1.9 \%$ & $6.7 \%$ & $5.3 \%$ & $10.4 \%$ & $9.2 \%$ \\
16 days & $0.0 \%$ & $0.0 \%$ & $2.9 \%$ & $1.9 \%$ & $6.6 \%$ & $5.3 \%$ & $10.3 \%$ & $9.1 \%$ \\
17 days & $0.0 \%$ & $0.0 \%$ & $2.8 \%$ & $1.8 \%$ & $6.5 \%$ & $5.2 \%$ & $10.2 \%$ & $9.1 \%$ \\
18 days & $0.0 \%$ & $0.0 \%$ & $2.7 \%$ & $1.7 \%$ & $6.4 \%$ & $5.1 \%$ & $10.1 \%$ & $9.0 \%$ \\
19 days & $0.0 \%$ & $0.0 \%$ & $2.6 \%$ & $1.6 \%$ & $6.3 \%$ & $5.0 \%$ & $10.0 \%$ & $8.9 \%$ \\
20 days & $0.0 \%$ & $0.0 \%$ & $2.5 \%$ & $1.6 \%$ & $6.2 \%$ & $5.0 \%$ & $9.9 \%$ & $8.8 \%$ \\
21 days & $0.0 \%$ & $0.0 \%$ & $2.4 \%$ & $1.5 \%$ & $6.1 \%$ & $4.9 \%$ & $9.8 \%$ & $8.8 \%$ \\
\hline
\end{tabular}

In the previous analysis, fixed rated power of storage was assumed, however it may vary from installation to installation and system to system. Here a sensitivity analysis is conducted to assess the influence of rated power of thermal storage on results. Figure 7 presents the impact of rated input power of thermal storage on the wind curtailment during winter season assuming $30 \%$ wind penetration. As can be seen, in this particular case, reducing the rated power to half slightly decreases the performance. This effect becomes steadily more pronounced with larger thermal storages. On the other hand, doubling the rated power of thermal storage would have negligible impact on curtailment. 


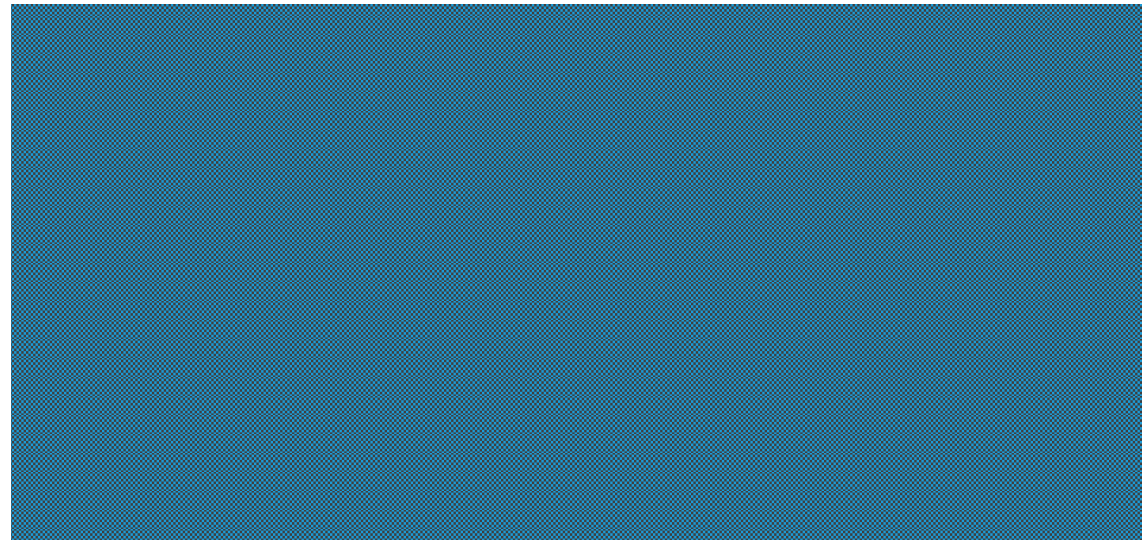

Figure 7. Impact of rated power of thermal storage on curtailment.

\subsection{Economic Impacts of the Increased Storage on Wind Penetration}

The wind generation revenue loss depends on the cost of curtailed renewable energy. In Finland, the wind generation curtailment cost is $83.5 € / \mathrm{MWh}$ which is based on the current feed-in tariff, whereas the cost of adding a customer-owned thermal storage is roughly estimated to be $2-3 € / \mathrm{L}$ (i.e., approximately $€ 1000$ for adding one day of storage). Using the above cost estimates with a discount rate of $7 \%$, and assuming the lifetime of distributed thermal storage unit to be 20 years, the equivalent annual discounted marginal cost of adding one day of thermal storage (300,000 units) in the system comes out to be $€ 5.1$ million and is assumed to increase linearly. On the other hand, the benefits (reduction in revenue loss from wind curtailment) as illustrated by Figure 8 starts to saturate as the storage capacity increases beyond a few days. It can be seen that 2 days (when wind penetration is $10 \%$ ) and about 6 days (when wind penetration $50 \%$ or more) of storage capacity will bring optimum benefits. The results are based on the example study and a comprehensive cost-benefit analysis, which is beyond the scope of this work, and would determine cost-optimal thermal storage in a given system.

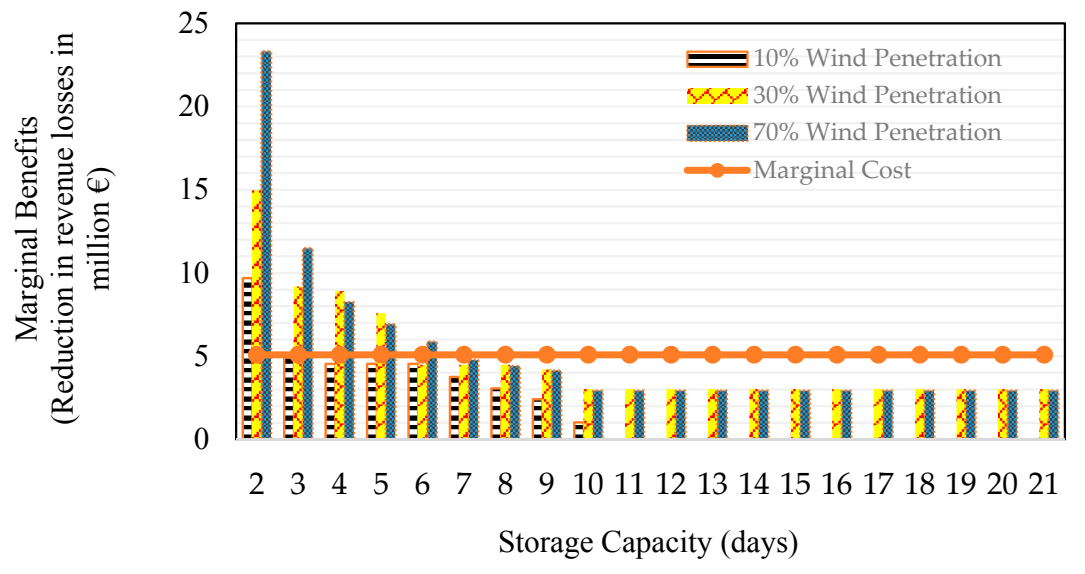

Figure 8. Economic assessment of the increased thermal storage for curtailment mitigation.

\subsection{Impact of Wind Uncertainty and Variability on Curtailment}

The basic results presented in Figure 6 are based on a single run of the wind time series. However, given the variability and uncertainty of wind, it is imperative to determine the confidence interval of the observed trends. For doing so, we repeated the basic study for multiple runs and calculated the mean path and the lower and upper confidence bounds. The approach was to calculate the 5 th and 95th percentiles for each storage capacity, such that $90 \%$ of the data should be within the calculated confidence bounds. In this context, Figure $9 a-d$ presents the statistical analysis of the results obtained 
for $10 \%, 30 \%, 50 \%$ and $70 \%$ respectively. As can be observed, the confidence intervals serve as good estimates of the storage capacity potential to mitigate curtailment.

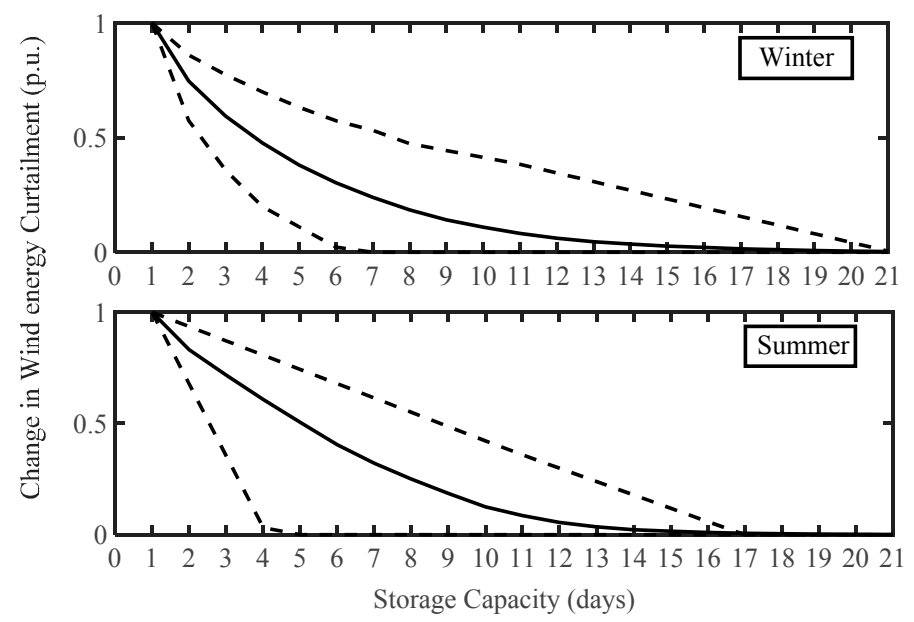

(a)

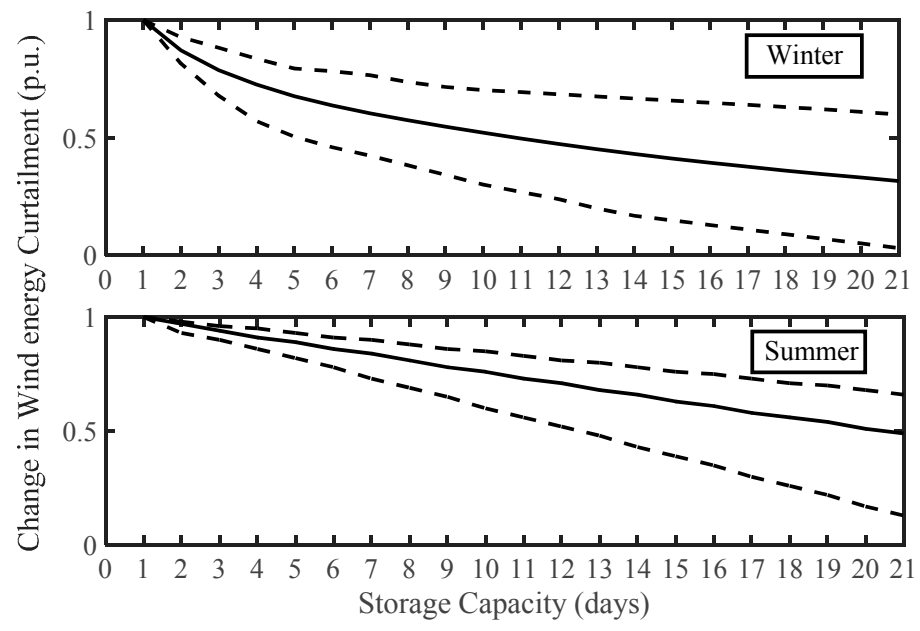

(b)

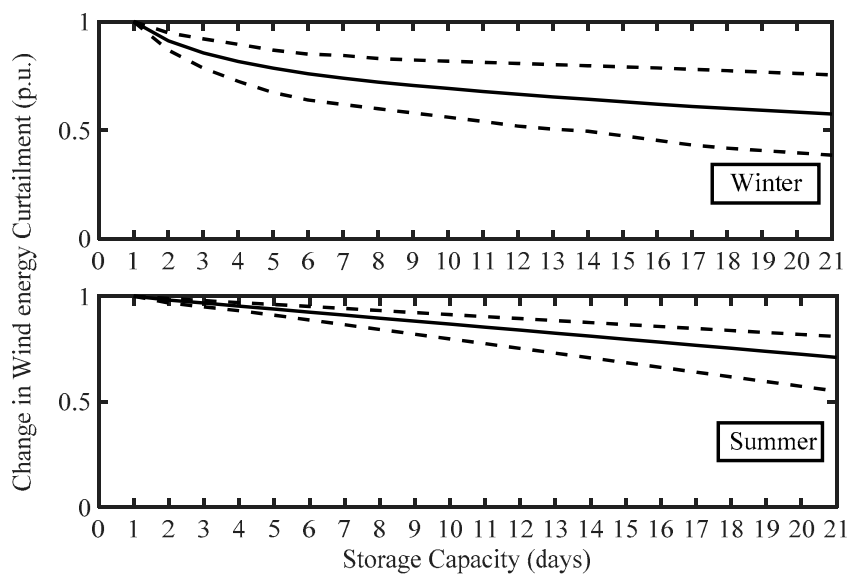

(c)

Figure 9. Cont. 


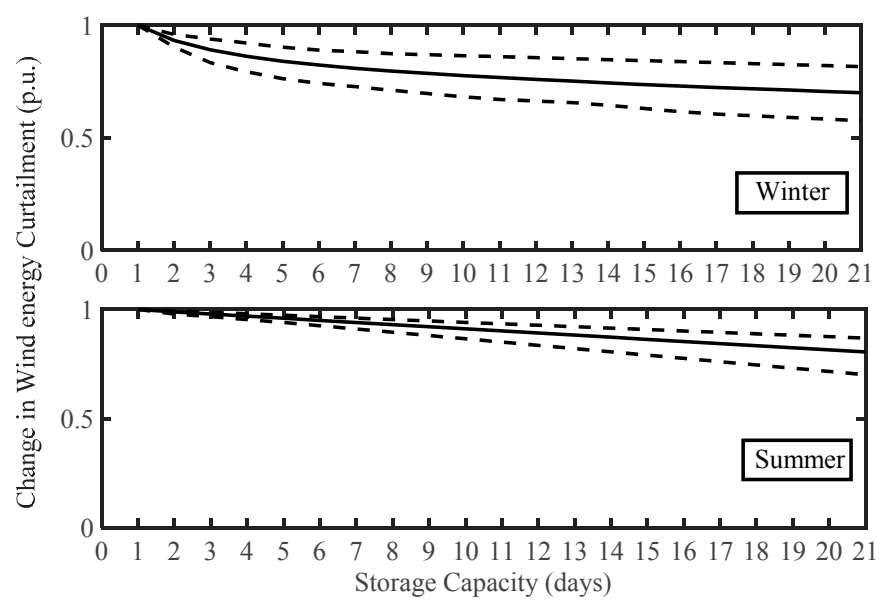

(d)

Figure 9. Impact of aggregating customer-owned thermal storages on curtailment (a) 10\% wind (b) $30 \%$ wind (c) $50 \%$ wind (d) $70 \%$ wind penetration in the system. (Solid line is the mean trend while dotted line shows 5 th and 95 th bounds on confidence interval).

\subsection{Optimal Thermal Storage Sizing Based on Desired Curtailment}

The impact of wind penetration in the system on the optimal storage size to achieve preferred curtailment level is investigated. In this sensitivity analysis, we consider only the winter season and determine the optimal energy capacity to reduce the curtailment to a certain level.

The optimal thermal storage to reduce the curtailment to levels of $5 \%, 3 \%$ and $1 \%$ are given in Table 2. It can be seen that higher storage capacity is required if a low level of curtailment is desired. It is to be noted that with a higher level of wind penetration in the system, it is infeasible for domestic thermal storages to mitigate renewable curtailment to the desired level. This limitation is because there is a demand limit at customer premises due to the network limits; hence increasing the storage size without increasing the rated charging power is infeasible in these cases.

Table 2. Optimal thermal storage sizing to mitigate curtailment w.r.t different level of wind penetration in the system.

\begin{tabular}{ccccc}
\hline \multirow{2}{*}{$\begin{array}{c}\text { Curtailment } \\
\text { Below }\end{array}$} & \multicolumn{4}{c}{ Optimal Storage Size } \\
\cline { 2 - 5 } & $\mathbf{1 0} \%$ Wind & $\mathbf{3 0} \%$ Wind & $\mathbf{5 0} \%$ Wind & $\mathbf{7 0} \%$ Wind \\
\hline $5 \%$ & 1 day & 2 days & 30 days & N/A \\
$3 \%$ & 1 day & 11 days & 55 days & N/A \\
$1 \%$ & 3 days & 32 days & N/A & N/A \\
\hline
\end{tabular}

\section{Conclusions}

Increased integration of wind generation in a power system will create technical challenges for the system operator including curtailment. Energy storage provides an opportunity to harness the excess production and utilize the stored energy during peak periods. This paper presents a framework to evaluate the potential benefits of aggregating domestic thermal storages for wind curtailment mitigation. The proposed framework is applied to the Finnish system considering multiple future scenarios of wind penetration in the system. The analysis demonstrated that aggregating customer-owned thermal storages presented a good opportunity to mitigate curtailment, however, the potential to harness excess wind production becomes saturated. The saturation trend is more dominant during the summer season as the low, flexible demand frequently coincides with a high generation period. Furthermore, it is observed that as the share of wind generation in the 
system soars beyond a certain level (30\% in this case), the flexibility to reduce curtailment via customer-owned thermal storages diminishes rapidly. Therefore, the technological development of large-scale centralized storage and collaboration with distributed energy resources is critical to mitigate renewable curtailment in future smart grids.

Acknowledgments: This work was supported by Aalto University's Sustainable Transition of European Energy Markets (STEEM) Project.

Author Contributions: Mubbashir Ali proposed the framework and performed the simulations. Jussi Ekström performed the wind generation time series modeling and statistical analysis on the results. Matti Lehtonen directed the work.

Conflicts of Interest: The authors declare no conflict of interest.

\section{Nomenclature}

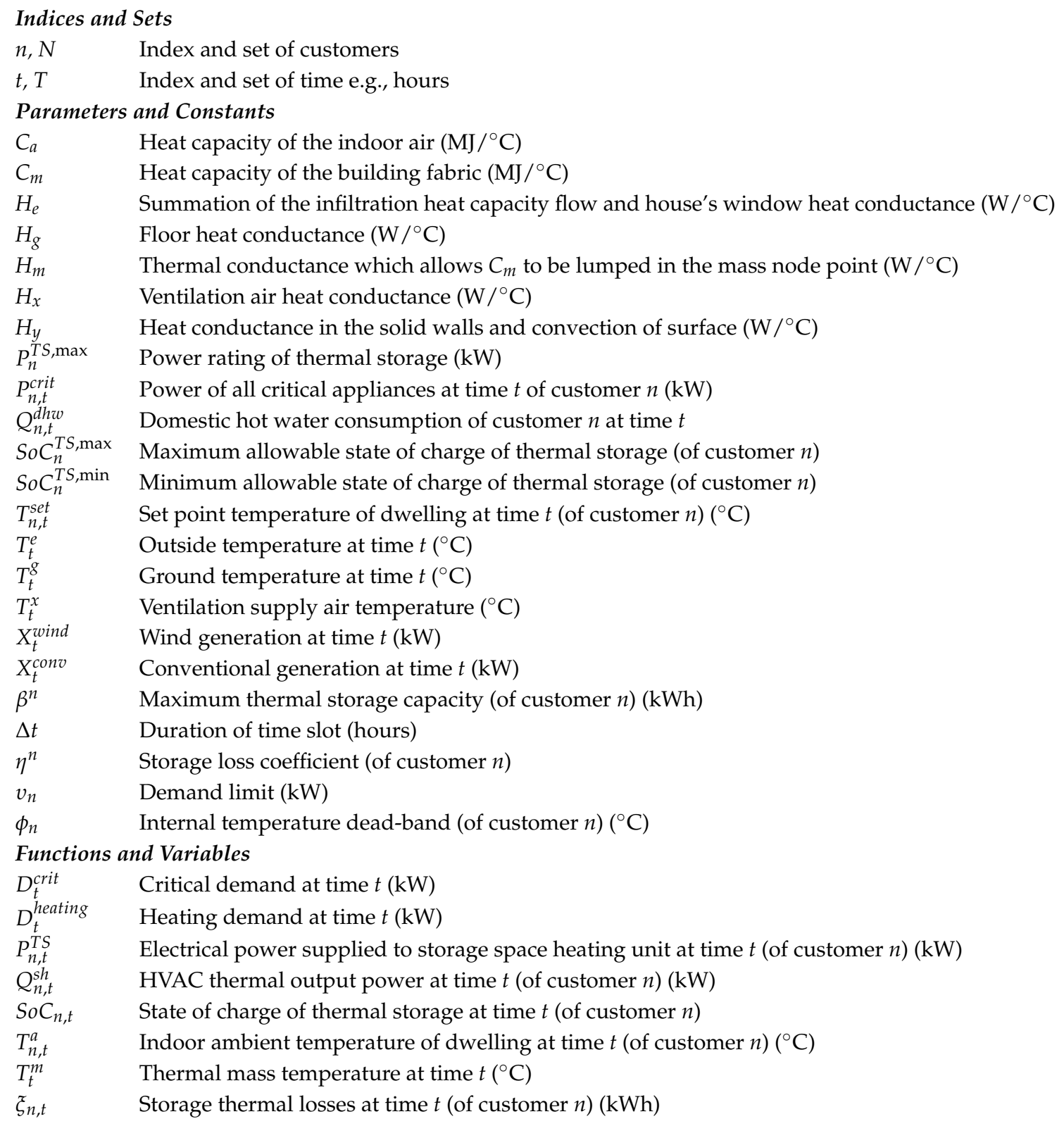




\section{References}

1. WindEurope. Available online: https://windeurope.org/about-wind/statistics/european/wind-in-power2016/ (accessed on 3 March 2017).

2. Bird, L.; Lewb, D.; Milligana, M.; Carlinic, E.M.; Estanqueirod, A.; Flynne, D.; Gomez-Lazarof, E.; Holttineng, H.; Menemenlish, N.; Orthsi, A.; et al. Wind and solar energy curtailment: A review of international experience. Renew. Sustain. Energy Rev. 2016, 65, 577-586. [CrossRef]

3. TWENTIES. Report on the Economic Impact of Enhanced Network Flexibility and New Solutions for Ancillary Services (Indicative Title); WindEurope: Brussels, Belgium, 2013.

4. Ali, M.; Ekström, J.; Alahäivälä, A.; Lehtonen, M. Assessing the Upward Demand Response Potential for Mitigating the Wind Generation Curtailment: A Case Study. In Proceedings of the 14th International Conference on the European Energy Market (EEM), Dresden, Germany, 6-9 June 2017.

5. McKenna, E.; Grünewald, P.; Thomson, M. Going with the wind: Temporal characteristics of potential wind curtailment in Ireland in 2020 and opportunities for demand response. IET Renew. Power Gener. 2015, 9, 66-77. [CrossRef]

6. Zhang, C.; Xu, Y.; Dong, Z.Y.; Wong, K.P. Robust Coordination of Distributed Generation and Price-Based Demand Response in Microgrids. IEEE Trans. Smart Grid 2017. [CrossRef]

7. Ali, M.; Degefa, M.; Humayun, M.; Safdarian, A.; Lehtonen, M. Increased Utilization of Wind Generation by Coordinating the Demand Response and Real-time Thermal Rating. IEEE Trans. Power Syst. 2016, 31, 3737-3746. [CrossRef]

8. Ochoa, L.F.; Dent, C.J.; Harrison, G.P. Distribution Network Capacity Assessment: Variable DG and Active Networks. IEEE Trans. Power Syst. 2010, 25, 87-95. [CrossRef]

9. Orfanos, G.A.; Georgilakis, P.S.; Hatziargyriou, N.D. Transmission Expansion Planning of Systems with Increasing Wind Power Integration. IEEE Trans. Power Syst. 2013, 28, 1355-1362. [CrossRef]

10. Cruz, M.R.M.; Fitiwi, D.Z.; Santos, S.F.; Catalão, P.S. Influence of distributed storage systems and network switching/reinforcement on RES-based DG integration level. In Proceedings of the 13th International Conference on the European Energy Market (EEM), Porto, Portugal, 6-9 June 2016; pp. 1-5.

11. Chaves-Avila, J.P.; Banez-Chicharro, F.; Ramos, A. Impact of support schemes and market rules on renewable electricity generation and system operation: The Spanish case. IET Renew. Power Gener. 2017, 11, 238-244. [CrossRef]

12. Alnaser, S.W.; Ochoa, L.F. Optimal Sizing and Control of Energy Storage in Wind Power-Rich Distribution Networks. IEEE Trans. Power Syst. 2016, 31, 2004-2013. [CrossRef]

13. Ke, X.; Lu, N.; Jin, C. Control and size energy storage systems for managing energy imbalance of variable generation resources. IEEE Trans. Sustain. Energy 2015, 6, 70-78. [CrossRef]

14. Cleary, B.; Duffy, A.; OConnor, A.; Conlon, M.; Fthenakis, V. Assessing the economic benefits of compressed air energy storage for mitigating wind curtailment. IEEE Trans. Sustain. Energy 2015, 6, 1021-1028. [CrossRef]

15. Makarov, Y.V.; Du, P.; Kintner-Meyer, M.C.W.; Jin, C.; Illian, H.F. Sizing Energy Storage to Accommodate High Penetration of Variable Energy Resources. IEEE Trans. Sustain. Energy 2012, 3, 34-40. [CrossRef]

16. Fernández-Blanco, R.; Dvorkin, Y.; Xu, B.; Wang, Y.; Kirschen, D.S. Optimal Energy Storage Siting and Sizing: A WECC Case Study. IEEE Trans. Sustain. Energy 2017, 8, 733-743. [CrossRef]

17. Albadi, M.H.; Al-Busaidi, A.S.; El-Saadany, E.F. Using PHES to facilitate wind power integration in isolated systems-Case study. In Proceedings of the 2017 IEEE International Conference on Industrial Technology (ICIT), Toronto, ON, Canada, 22-25 March 2017; pp. 469-474.

18. Ekström, J.; Koivisto, M.; Mellin, I.; Millar, J.; Saarijärvi, E.; Haarla, L. Assessment of Large Scale Wind Power Generation with New Generation Locations without Measurement Data. Renew. Energy 2015, 83, 362-374. [CrossRef]

19. Koivisto, M.; Ekström, J.; Seppänen, J.; Mellin, I.; Millar, J.; Haarla, L. A statistical model for comparing future wind power scenarios with varying geographical distribution of installed generation capacity. Wind Energy 2016, 19, 665-679. [CrossRef]

20. Ministry of the Environment. C3: Finnish Code of Building Regulations (Thermal Insulation in a Building); Ministry of the Environment: Helsinki, Finland, 2010. (In Finnish)

21. Finnish Meteorological Institute. Available online: http:/ /en.ilmatieteenlaitos.fi/ (accessed on 2 March 2017). 
22. Ali, M.; Safdarian, A.; Lehtonen, M. Demand response potential of HVAC load considering user preferences. In Proceedings of the Innovative Smart Grid Technologies Conference Europe (ISGT-Europe), Istanbul, Turkey, 12-15 October 2014; pp. 1-6.

23. Alahaivala, A.; Saarijärvi, E.; Lehtonen, M. Modeling electric vehicle charging flexibility for the maintaining of power balance. Int. Rev. Electr. Eng. 2013, 8, 1759-1769. 